\title{
Analisis Produktivitas dan Beban Kerja Operator Produksi dengan Metode Work Sampling dan NASA-TLX di PT. Tokai Dharma Indonesia Plant II
}

\author{
Agus Sutiko ${ }^{1}$, Hadi Suprapto ${ }^{2}$, Didi Zainuddin ${ }^{3}$ \\ 1,2,3 Program Studi Teknik Industri, Universitas Indraprasta PGRI Jakarta
}

*Corresponding author: agus.sutiko1@ gmail.com

\section{ARTICLE INFORMATION \\ Received: 03 Juni 2021 \\ Revised: 06 Agustus 2021 \\ Accepted: 22 Agustus 2021 \\ Available online: 28 September 2021}

\section{KEYWORDS}

Sampling Pekerjaan,

Produktivitas,

NASA-TLX.

\begin{abstract}
A B S T R A $\mathbf{K}$
PT. Tokai Dharma Indonesia adalah perusahaan yang bergerak di bidang manufaktur dan distributor korek api gas terbesar di Indonesia dengan merk korek Tokai. Efektivitas adalah merupakan derajat pencapaian output dari sistem produksi dan efisiensi adalah ukuran yang menunjuk sejauh mana sumber-sumber daya digunakan dalam proses produksi untuk menghasilkan output Work sampling secara umum dapat dikatakan sebagai suatu teknik dimana banyak dilakukan pengamatanpengamatan instan dalam periode waktu dari suatu kelompok pekerja, mesin atau proses. Dan NASATLX merupakan metode yang digunakan untuk menganalisa beban kerja mental Dari hasil di atas maka kita dapat menganalisa hasil produktivitas dan beban kerja operator produksi di PT. Tokai Dharma Indonesia Plant II, dimana secara keseluruhan pekerja yang memiliki Persentase produktif tertinggi yaitu dengan jumlah $74 \%$ pekerja J (Fatma) Sedangkan pekerja dengan persentase terendah adalah pekerja C (Rizaldi Fadilah) dengan nilai $64 \%$. Penyebab terjadinya produktivitas rendah yaitu karena adanya aktivitas mengobrol dan sering istirahat serta menunggu mesin berjalan. Untuk beban kerja mental paling tinggi yang di hitung menggunakan metode NASA-TLX adalah pekerja E (Haryadi) dengan skor rata-rata $72 \%$ yang berarti tinggi. Yang meyebabkan tingginya beban adalah karena karyawan terlalu banyak mengejar target serta beban material yang cukup berat Solusi untuk mengatasi beban kerja yang tinggi yaitu dengan menyesuaikan kemampuan fisik dan mental pekerja serta memberi pekerja kesempatan pekerja untuk mengembangkan karir dengan mengikutkan beberapa pekerja untuk melakukan pelatihan agar terbiasa dan dapat meningkatkan produktivitas
\end{abstract}

\section{INTRODUCTION}

Perkembangan industri di era globalisasi ini sangat pesat. Hal ini dapat diketahui dari persaingan antar perusahaan yang semakin meningkat dan lebih ketat. Bukan hanya perusahaan bersekala besar dan internasional, bahkan perusahaan kecil pun juga mengalami persaingan global. PT. Tokai Dharma Indonesia adalah perusahaan yang bergerak di bidang manufaktur dan distributor yaitu sebagai salah satu produsen korek api gas terbesar di Indonesia dengan merk korek Tokai. PT. Tokai Dharma Indonesia selalu berkomitmen untuk melakukan inovasi dengan standar kualitas dan keamanan yang memenuhi standar di Indonesia. Sebagai perusahaan yang bergerak di bidang industri, PT Tokai harus mampu meningkatkan produktivitasnya agar perusahaan dapat bersaing dalam dunia perdagangan dan usahanya tetap berjalan dengan lancar. Produktifitas berkaitan dengan beban kerja dan efektivitas pemanfaatan sumberdaya (input) dalam memproduksi (output). Efektivitas adalah merupakan derajat pencapaian output dari sistem produksi dan efisiensi adalah ukuran yang menunjuk sejauh mana sumber-sumber daya digunakan dalam proses produksi untuk menghasilkan output.
Karyawan adalah salah satu sumber daya yang sangat dibutuhkan dalam suatu organisasi, harus diakui dan diterima manajemen, karena peningkatan produktivitas kerja hanya mungkin dilakukan oleh manusia. Produktivitas kerja merupakan kemampuan mengasilkan barang dengan sumber daya yang tersedia, jika produktivitas kerja yang ada pada perusahaan rendah, perusahaan tidak akan mampu menghasilkan pencapaian kerja sesuai dengan target yang telah ditentukan, dan dengan hal itu pula perusahaan tidak dapat mengikuti arus persaingan yang ada. Karyawan merupakan manusia biasa yang juga memiliki rasa lelah. Rasa lelah dapat ditimbulkan dari berbagai macam hal, misalnya dari beban kerja pekerjaan yang dilakukan sehari-hari. Beban kerja adalah suatu istilah yang digunakan untuk menyebut harga dari pencapaian suatu target kegiatan.

Pengertian produktivitas tersebut biasanya dihubungkan dengan produktivitas pekerja dan dapat dijabarkan sebagai perbandingan antara hasil kerja dan jam kerja. Pengukuran produktivitas tenaga kerja sulit dilakukan secara akurat dan memerlukan tenaga dan biaya yang besar. Oleh karena itu pengukuran produktivitas tenaga kerja di perusahaan dapat dilakukan dengan 
metode-metode pendekatan, yang salah satunya adalah metode work sampling dan NASA Task Load Index. Work sampling secara umum dapat dikatakan sebagai suatu teknik dimana banyak dilakukan pengamatan-pengamatan instan dalam periode waktu dari suatu kelompok pekerja, mesin atau proses. Dan NASA-TLX merupakan metode yang digunakan untuk menganalisa beban kerja mental yang di kembangkan oleh Sanda G. Harp dari NASAAmesh research center dan Lowell E. staveland dari San Jose State Uniersity pada tahun 1981.

\section{METHOD}

\section{A. Metode Pengumpulan Data}

Metode pengumpulan data yang digunakan pada penelitian ini yaitu : wawancara, observasi serta studi pustaka.

\section{B. Flowchart Penelitian}

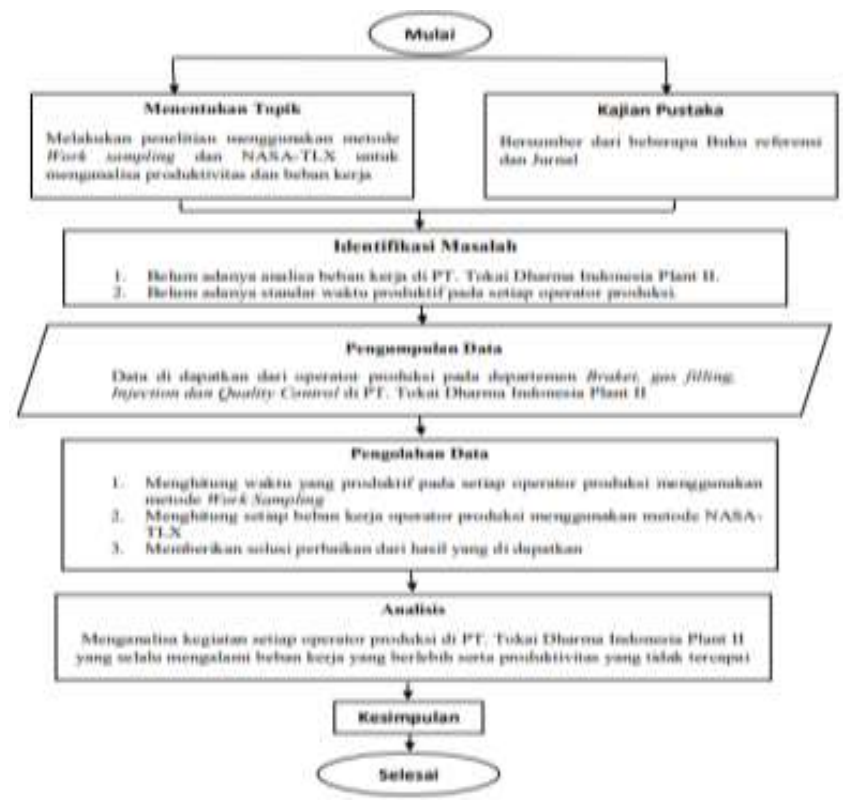

Gambar 1. Flowchart Penelitian

\section{RESULTS AND DISCUSSION}

Setelah Dalam penelitian ini bertujuan untuk menganalisa produktivitas dan beban kerja pada operator produksi di PT. Tokai Dharma Indonesia Plant II dengan menggunakan metode Work Sampling dan NASA-TLX. Work Sampling sendiri merupakan suatu teknik untuk mengadakan sejumlah besar pengamatan terhadap aktivitas kerja dari mesin, proses pekerja atau operator. NASA-TLX sendiri merupakan metode yang digunakan untuk penilaian multidimensi subjektif yang banyak digunakan untuk menilai beban kerja yang dirasakan untuk menilai efektivitas tugas, sistem, atau tim aspek kinerja lainnya.

1. Teknik Analisis Data

Setelah data diperoleh melalui proses observasi secara langsung maupun dari beberapa buku referensi/jurnal, kemudian dilakukan pengolahan data. Agar pelaksanaan penelitian dapat berjalan dengan mudah serta sesuai dengan tujuan yang ingin dicapai, maka diperlukan langkah pemecahan yang baik. Dalam pelaksanaan penelitian kali ini, khususnya untuk mengamati produktivitas dan beban kerja karyawan penulis menggunaan metode work sampling yaitu:

a. Digunakan untuk pengukuran waktu kerja bagi pekerja langsung, dan mesin.

b. Pengamatan dilakukan secara random (acak).

c. Sangat cocok untuk pekerjaan yang sifatnya tidak berulang.

d. Urutan pekerjaannya tidan menentu.

e. Waktu penyelesaiannya relatif panjang.

Terdapat 90 kali pengamatan dalam sehari. Jam kerja operator 1 shift adalah 8 jam, penulis membagi satuan pengamatan menjadi 5 menit yang di tentukan dari pengamatan minggu pertama, maka di dapat 98 kali pengamatan jika dilakukan secara utuh tetapi penulis hanya mengambil 90 kali pengamatan 8 kali nya itu digunakan untuk jam istirahat. Pengamatan tersebut di lakukan selama 5 hari dalam satu depatemen yang berisi 3 karyawan. Penulis mendapatkan data yang cukup maka di lakukan rekapitulasi pada lembar pengamatan.

2. Langkah-langkah melakukan analisa produktivitas dan beban kerja menggunakan metode work sampling dan NASA-TLX adalah sebagai berikut:

a. Batas Kontrol Atas (BKA)

Sebuah grafik atas yang memberi gambaran tentang prilaku proses. Batas kontrol ini digunakan untuk memahami apakah sebuah proses manufakturing berjalan dalam kondisi yang terkontrol, seragaman dan tidak melebihi batas kontrol atas. Berikut adalah rumus BKA:

$$
\mathrm{BKA}=\bar{P}+\mathrm{k} \sqrt{\frac{P(1-P)}{n}}
$$

Dimana:

$$
\begin{aligned}
& \bar{P}=\text { Persentase rata-rata produktif } \\
& \mathrm{k}=\text { Tingkat keyakinan } \\
& \mathrm{n}=\text { Ukuran sample/data }
\end{aligned}
$$

b. Batas Kontrol bawah (BKB)

Sebuah grafik atas yang memberi gambaran tentang prilaku proses. Batas kontrol ini digunakan untuk memahami apakah sebuah proses manufakturing berjalan dalam kondisi yang terkontrol, seragaman dan tidak melebihi batas kontrol bawah. Berikut adalah rumus BKB:

$$
\begin{aligned}
& \text { BKB }=\bar{P}-\mathrm{k} \sqrt{\frac{P(1-P)}{n}} \\
& \text { Dimana: } \\
& \bar{P}=\text { Persentase rata-rata produktif } \\
& \mathrm{k}=\text { Tingkat keyakinan } \\
& \mathrm{n}=\text { Ukuran sample/data }
\end{aligned}
$$

c. Persentase rata-rata produktif

Persentase produktif berfungsi untuk mengetahui produktivitas rata-rata operator dalam bekerja yang dapat di cari dengan rumus:

$$
\bar{P}=\frac{\sum p 1+p i 2+p i 3+p i 4+p i 5}{\sum P}
$$

Dimana:

$$
\sum p 1=\text { Persentase produktif perhari }
$$


$\Sigma p=$ Banyak Hari Pengamatan

d. Uji Kecukupan Data (N')

Uji kecukupan data diperlukan untuk memastikan bahwa data yang telah dikumpulkan dan di sajikan dalam laporan pengamatan cukup secara objektif. Idealnya pengukuran harus dilakukan dalam jumlah banyak, bahkan sampai jumlah yang tidak terhigga agar data hasil pengukuran layak untuk digunakan. Berikut adalah rumus uji kecukupan data:

Dimana:

$$
N^{\prime}=\frac{k^{2}(1-\bar{p})}{s^{2} \cdot \bar{p}}
$$

$$
\begin{aligned}
& \mathrm{k}=\text { Tingkat keyakinan } \\
& \bar{P}=\text { Persentase rata-rata produktif } \\
& \mathrm{S}=\text { Drajat ketelitian }
\end{aligned}
$$

e. Jumlah pengamatan total $(\mathrm{N})$

Pengamatan total berfungsi untuk mengetahui jumlah kegiatan yang produktif pada setiap operator produksi, rumus pengamatan total adalah sebagai berikut:

$$
\begin{aligned}
& \text { Dimana: } \\
& \mathrm{N}=\mathrm{N}=\mathrm{N} 1+\mathrm{N} 2+\mathrm{N} 3+\mathrm{N} 4+\mathrm{N} 5 \\
& \text { penelitian }
\end{aligned}
$$

f. Waktu Siklus (WS)

Waktu siklus adalah waktu antara penyelesaian dari dua pertemuan berturut-turut dalam artian waktu siklus merupakan hasil pengamatan secara langsung yang tertera dalam stopwatch. Berikut adalah rumus waktu siklus:

$$
\text { Ws } \frac{\text { jumlah menit produktif }}{\text { jumlah barang yang di hasilkan }}
$$

g. Waktu Normal (WN)

Waktu normal adalah waktu kerja yang telah mempertimbangkan faktor penyesuaian, yaitu waktu siklus rata-rata dikalikan dengan faktor penyesuaian. Waktu normal untuk suatu elemen operasi kerja adalah semata-mata menunjukan bahwa seorang operator yang berkualifikasi baik akan bekerja menyelesaikan pekerjaan pada tempo kerja yang normal. Berikut adalah rumus waktu normal:

\section{$\mathrm{WN}=$ Waktu siklus $X$ Faktor penyesuaian}

h. Waktu Baku (Wb)

Waktu baku adalah waktu keseluruhan yang diperlukan untuk menyelesikan suatu produk, berikut adalah rumus waktu baku:

$$
\begin{aligned}
& \mathrm{Wn}=\text { Waktu normal } \\
& \mathrm{All}=\text { kelonggaran }
\end{aligned}
$$$$
\text { Dimana: }
$$$$
\mathrm{Wb}=\mathrm{Wn} \cdot \frac{100 \%}{100 \%-a l l}
$$

i. Beban kerja (Bk)

Beban kerja adalah sejumlah proses atau kegiatan yang harus diselesaikan oleh seorang pekerja dalam jangka waktu tertentu. Apabila seorang pekerja mampu menyelesaikan dan menyesuaikan diri terhadap sejumlah tugas yang diberikan, maka hal tersebut tidak menjadi suatu beban kerja. Berikut adalah rumus beban kerja:

$$
\mathrm{BK}=\frac{\text { waktu baku }}{\text { total waktu pengamatan }} \times 100 \%
$$

j. Pembobotan Indikator berpasangan NASA-TLX Pada bagian ini responden diminta untuk memilih salah satu dari dua indikator yang dirasakan lebih dominan menimbulkan beban kerja mental terhadap pekerjaan tersebut. Kuesioner yang diberikan

\begin{tabular}{|c|c|c|}
\hline INDIKATOR & KODE & PEN.JELASAN \\
\hline $\begin{array}{l}\text { Kebutuhan } \\
\text { Mental }\end{array}$ & $\mathrm{KM}$ & $\begin{array}{l}\text { Seberapa sering pekerjaan anda melibatkan kerja } \\
\text { otak, seperti mengambil keputusan, berfikir cepat, } \\
\text { atau mengingat. }\end{array}$ \\
\hline $\begin{array}{l}\text { Kebutuhan } \\
\text { Fisik }\end{array}$ & $\mathrm{KF}$ & $\begin{array}{l}\text { Seberapa sering pekerjaan anda melibatkan kerja } \\
\text { otot, seperti mengangkat, mengendarai kendaraan, } \\
\text { mendorong, dan lain-lain. }\end{array}$ \\
\hline $\begin{array}{c}\text { Kebutuhan } \\
\text { Waktu }\end{array}$ & KW & $\begin{array}{l}\text { Seberapa besar tekanan yang anda rasakan mengenai } \\
\text { waktu penyelesaian pekerjaan, apakah pekerjaan } \\
\text { perlahan tapi santai ataukah cepat tapi melelahkan? }\end{array}$ \\
\hline $\begin{array}{l}\text { Performa } \\
\text { Kerja }\end{array}$ & PK & $\begin{array}{l}\text { Seberasa besar keberhasilan yang anda capai dan } \\
\text { seberapa puas yang anda rasakan mengenai } \\
\text { keberhasilan anda. }\end{array}$ \\
\hline $\begin{array}{l}\text { Tingkat } \\
\text { Frustasi }\end{array}$ & TS & $\begin{array}{l}\text { Scberapa aman, tidak putus asa, tersinggung, } \\
\text { terganggu, di bandingkan dengan perasaan aman, } \\
\text { nyaman, dan kepuasan diri yang di rasakan. }\end{array}$ \\
\hline $\begin{array}{l}\text { Usaha Fisik } \\
\text { dan Mental }\end{array}$ & U & $\begin{array}{l}\text { Seberapa besar pekerjaan anda yang berhubungan } \\
\text { dengan pekerjan fisik dan pekerjaan yang } \\
\text { memerlukan pemikiran dilakukan untuk } \\
\text { menyelesaikan pekerjaan anda. }\end{array}$ \\
\hline
\end{tabular}
berbentuk perbandingan berpasangan yang terdiri dari 15 perbandingan berpasangan. Dari kuesioner ini di hitung tally dari setiap indikator yang dirasakan paling berpengaruh. Jumlah tally ini kemudian akan menjadi bobot untuk tiap indikator beban kerja mental. Kuesioner ini terdiri dari dua jenis pertanyaan yang keduanya menggunakan indikator yang sama. Berikut adalah defisini dari masing-masing indiktor.

Tabel I

Penjelasan Indikator Berpasangan

(Sumber: Kuesioner Pembobotan Indikator

\section{Berpasangan)}

Petunjuk Pengisian, berilah tanda centang $(\sqrt{ })$ pada salah satu indikator dari setiap perbandingan berpasangan yang paling berpengaruh dalam melakukan pekerjaan.

Tabel II

Pembobotan Berpasangan

\begin{tabular}{ccccc}
\hline NO & INDIKATOR & KODE & INDIKATOR & KODE \\
\hline 1 & Kebutuhan Fisik & KF & Kebutuhan Mental & KM \\
2 & Kebutuhan Waktu & KW & Kebutuhan Mental & KM \\
3 & Performansi Kerja & PK & Kebutuhan Mental & KM \\
4 & Usaha Fisik dan Mental & U & Kebutuhan Mental & KM \\
5 & Tingkat Frustasi & TS & Kebutuhan Mental & KM \\
6 & Kebutuhan Waktu & KW & Kebutuhan Fisik & KF \\
7 & Performansi Kerja & PK & Kebutuhan Fisik & KF \\
8 & Usaha Fisik dan Mental & U & Kebutuhan Fisik & KF \\
9 & Tingkat Frustasi & TS & Kebutuhan Waktu & KW \\
10 & Performansi Kerja & PK & Kebutuhan Fisik & KF \\
11 & Usaha Fisik dan Mental & U & Kebutuhan Waktu & KW \\
12 & Tingkat Frustasi & TS & Kebutuhan Waktu & KW \\
13 & Usaha Fisik dan Mental & U & Performansi Kerja & PK \\
14 & Tingkat Frustasi & TS & Performansi Kerja & PK \\
15 & Usaha Fisik dan Mental & U & Tingkat Frustasi & TS \\
\hline
\end{tabular}

(Sumber: Kuesioner Pembobotan Indikator Berpasangan) 
k. Pemberian Rating

Pada bagian ini responden diminta memberi rating terhadap 6 indikator beban mental dengan rentang 0-100. Nilai yang diberikan adalah subjektif tergantung pada beban mental yang rasakan oleh responden tersebut.

Tabel III

Lembar pembobotan nilai

\begin{tabular}{|c|c|c|}
\hline INDIKATOR & PERTANYAAN & RATING \\
\hline Kebutuhan & Menurut anda, seberapa besar usaha mental yang & \\
\hline Mental (KM) & $\begin{array}{l}\text { dibutuhkan untuk pekerjaan anda sebagai } \\
\text { operator produksi? }\end{array}$ & \\
\hline $\begin{array}{l}\text { Kebutuhan Fisik } \\
\text { (KF) }\end{array}$ & $\begin{array}{l}\text { Menurut anda, seberasa besar usaha fisik yang } \mathrm{di} \\
\text { butulkkan untuk pekerjaan anda? }\end{array}$ & \\
\hline $\begin{array}{c}\text { Kebutuhan } \\
\text { Waktu (KW) }\end{array}$ & $\begin{array}{l}\text { Menurut anda, seberapa besar tekanan yang anda } \\
\text { rasakan berkaitan dengan waktu untuk } \\
\text { melakukan pekerjaan anda? }\end{array}$ & \\
\hline Performansi & Menurut anda, seberasa besar tingkat & \\
\hline Kerja (PK) & $\begin{array}{l}\text { keberhasilan anda dalam melakukan pekerjaan } \\
\text { anda? }\end{array}$ & \\
\hline $\begin{array}{l}\text { Tingkeat Frustasi } \\
\text { (TS) }\end{array}$ & $\begin{array}{l}\text { Menurut anda, seberapa becar keeemasan, } \\
\text { perasaan tekanan, dan stress yang ada rasakan } \\
\text { berkaitan dengan waktu untuk melakukan } \\
\text { pekerjaan anda? }\end{array}$ & \\
\hline $\begin{array}{l}\text { Usaha Fisik dan } \\
\text { Mental (U) }\end{array}$ & $\begin{array}{l}\text { Menurut anda, seberapa besar kerja mental dan } \\
\text { fisik yang di butuhkan untuk menyelesaikan } \\
\text { pekerjaan anda? }\end{array}$ & \\
\hline
\end{tabular}

(Sumber: Kuesioner nilai beban kerja)

1. Menghitung Produk

Produk diperoleh dengan cara mengalikan rating dengan bobot faktor dengan masing-masing indikator. Dengan demikian di hasilkan 6 nilai produk indikator.

m. Menghitung Weight Work Load (WWL)

Setelah responden mengisi kuesioner pembobotan dan rating selanjutnya peneliti menghitung WWL atau menghitung jumlah hasil perkalian antara rating dan bobot.

\section{$\mathrm{WWL}=$ Rating $x$ Bobot}

n. Menghitung Rata-rata WWL

Menghitung rata-rata WWL berdasarkan urutan perhitungan di atas.

$$
\text { Beban Kerja Mental }=\frac{(\text { Rating } x \text { Bobot })}{15}
$$

Penentuan klasifikasi beban kerja mental berdasarkan interprestasi hasil nilai skor beban kerja mental. Adapun klasifikasi tersebut terdapat pada tabel dibawah ini:

Tabel IV

Skala Penilaian Kuesioner NASA-TLX

\begin{tabular}{ccc}
\hline Nomor & Range Nilai & Kategori Beban Kerja \\
\hline 1 & $0 \%-9 \%$ & Rendah \\
2 & $10 \%-29 \%$ & Sedang \\
3 & $30 \%-49 \%$ & Agak Tinggi \\
4 & $50 \%-79 \%$ & Tinggi \\
5 & $80 \%-100 \%$ & Tinggi Sekali \\
\hline
\end{tabular}

(Sumber: Meshkati,1988)

Penulis mendapatkan tugas untuk mengamati produktivitas dan beban kerja karyawan bagian departemen injection, filling gas, braket, dan quality control. Hasil pekerjaan ini meliputi lembar penilaian lembar data yang di ambil ketika penelitian di PT. Tokai Dharma Indonesial Plant II, meliputi lembar pengamatan terhadap 12 orang pekerja (3 pekerja departemen Injection, 3 pekerja departemen Filling Gas, 3 pekerja departemen Braket, dan 3 pekerja departemen Quality Control) satu departemen membutuhkan waktu selama 5 hari. Lembar data pada lenbar data yang dapat di lihat pada lampiran 1 hingga lampiran 48 berisi pengambilan data dengan metode work sampling sesuai dengan masing-masing 1 hari berjumlah 90 data. Seperti yang sudah di jelaskan sebelumnya, satuan waktu yang di gunakan sejumlah 5 menit. Untuk keseluruhan pekerja data di ambil minggu pertama untuk departemen Injection selama 5 hari sebanyak 3 orang, minggu ke 2 untuk departemen Filling Gas selama 5 hari sebanyak 3 orang, minggu ke 3 untuk departemen Braket selama 5 hari sebanyak 3 oranng, minggu ke 4 untuk departemen Quality Control selama 5 hari sebanyak 3 orang. Perhitungan persentase produktivitas untuk masingmasing pekerja dilakukan dengan menjumlahkan keseluruhan persentase produktif pada keseluruhan hari pengamatan di PT. Tokai Dharma Indonesia Plant II kemudian di bagi dengan jumlah hari yaitu 5 hari, untuk lebih jelasnya bisa di lihat pada tabel di bawah ini:

3. Perhitungan Work Sampling Pekerja A

Tabel V

Persentase Produktif Pekerja A

\begin{tabular}{|c|c|c|c|c|c|c|}
\hline \multirow[t]{2}{*}{ Kegiatan } & \multicolumn{5}{|c|}{ Hari Ke - } & \multirow[t]{2}{*}{ Jumlah } \\
\hline & 1 & 2 & 3 & 4 & 5 & \\
\hline Produktif & 59 & 66 & 62 & 64 & 64 & 315 \\
\hline Tidak & 31 & 24 & 28 & 26 & 26 & 135 \\
\hline \multicolumn{7}{|l|}{ Produktif } \\
\hline Total & 90 & 90 & 90 & 90 & 90 & 450 \\
\hline Produktif & 0,66 & 0,73 & 0,69 & 0,71 & 0,71 & 0,70 \\
\hline
\end{tabular}

(sumber: Lembar pengamatan work sampling pekerj A)

a. Perhitungan Persentase Produktif (Pi)

$$
\begin{array}{ll}
\text { Hari Pertama }\left(P_{1}\right) & \bar{P}_{i}=\frac{\sum P i}{k} \\
& \bar{P}_{1}=\frac{59}{90}=0,66 \\
\text { Hari Kedua }\left(P_{2}\right) & \bar{P}_{i}=\frac{\sum P i}{k} \\
& \bar{P}_{2}=\frac{66}{90}=0,73 \\
\text { Hari Ketiga }\left(P_{3}\right) & \bar{P}_{i}=\frac{\sum P i}{k} \\
& \bar{P}_{3}=\frac{62}{90}=0,69 \\
\text { Hari Keempat }\left(P_{4}\right) & \bar{P}_{i}=\frac{\sum P i}{k} \\
& \bar{P}_{4}=\frac{64}{90}=0,71 \\
\text { Hari Kelima }\left(P_{5}\right) & \bar{P}_{i}=\frac{\sum P i}{k} \\
& \bar{P}_{5}=\frac{64}{90}=0,71
\end{array}
$$

b. Perhitungan persentase produktif rata-rata

$$
\bar{P}_{i}=\frac{\sum P i}{k}=\frac{0,66+0,73+0,69+0,71+0,71}{5} \times 100 \%
$$

https://doi.org/10.30998/joti.v3i2.10026 


$$
=70 \%=0,70
$$

c. Uji keseragaman data

$$
\begin{aligned}
\mathrm{BKA} & =\bar{P}+3 \sqrt{\frac{P(1-P)}{n}} \\
& =0,70+3 \sqrt{\frac{0,70(1-0,70)}{90}}=0,84 \\
\mathrm{BKB} & =\bar{P}-3 \sqrt{\frac{P(1-P)}{n}} \\
& =0,70-3 \sqrt{\frac{0,70(1-0,70)}{90}}=0,55
\end{aligned}
$$

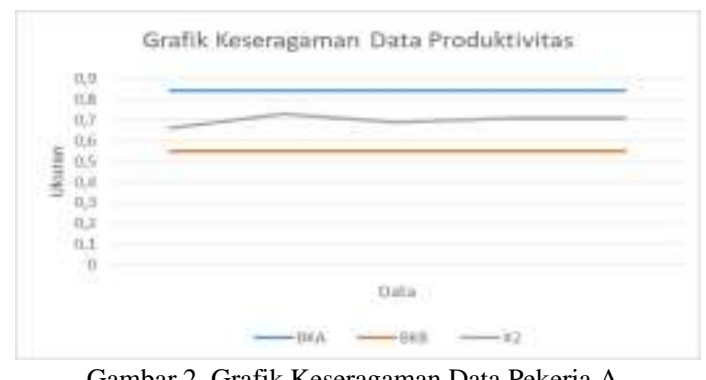

Gambar 2. Grafik Keseragaman Data Pekerja A

Karena data dari $\mathrm{x}$ tidak melebihi BKA dan BKB atau tidak out off control maka data dinyatakan seragam.

d. Uji Kecukupan Data

$$
\begin{aligned}
& \begin{array}{l}
a= \\
\mathrm{k}=
\end{array} \\
& \mathrm{s}=0,05 \\
& \bar{P}=\frac{\sum p i+p i 2+p i 3+p i 4+P i 5}{\sum P} \\
& \quad=\frac{59+66+62+64+64}{(31+24+28+28)+(59+66+62+64+64)} \\
& \quad=\frac{315}{450}=0,70 \\
& \quad N^{\prime}=\frac{k^{2}(1-\bar{p})}{s^{2} \cdot \bar{p}}=\frac{2^{2}(1-0,70)}{0,05.0,70}=34
\end{aligned}
$$

Dari perhitungan diatas dapat di ketahui bahwa N'< N yaitu $34<450$ maka data yang di gunakan cukup.

e. Perhitungan Beban Kerja

1) Jumlah pengamatan total selama 5 hari $\mathrm{N}=\mathrm{N} 1+\mathrm{N} 2+\mathrm{N} 3+\mathrm{N} 4+\mathrm{N} 5$

$=90+90+90+90+90$

$=450$

2) Jumlah kegiatan produktif

$=\mathrm{p} \overline{\mathrm{x}} \mathrm{N}$

$=0,70 \times 450$

$=315$

3) Jumlah menit pengamatan $=\left(\sum\right.$ hari $\times 1$ jam kerja x 60 menit $)-(40$ menit/istirahat $x 5$ hari)

$=(5 \times 8 \times 60)-(200$ menit $)$

$=2200$ menit $=37$ jam

4) Jumlah menit produktif $\mathrm{p}^{-} \mathrm{x}$ jumlah menit pengamatan $=0,70 \times 2200$ menit $=1540$ menit

5) Jumlah barang yang dihasilkan selama 5 hari pengamatan:

Hari pertama $=32.500$ unit

Hari kedua $=36.200$ unit

Hari ketiga $=35.700$ unit

Hari keempat $=39.200$ unit

Hari kelima $=41.000$ unit

$$
=184.600 \text { unit }
$$

6) Perhitungan waktu siklus

Ws $\frac{\text { jumlah menit produktif }}{\text { jumlah barang yang di hasilkan }}$

$=\frac{1540}{184600}=0,01$ Menit/Produk

7) Perhitungan waktu normal (Wn)

$$
\mathrm{Wn}=\mathrm{Ws} \times \mathrm{Rf}
$$

Faktor penyesuaian :

$$
\mathrm{Rf}=\mathrm{P} 1 \times \mathrm{P} 2
$$

Keterampilan : Excelent $(\mathrm{B} 1)=+0,11$

Usaha : Good $(\mathrm{C} 1) \quad=+0,05$

Kondisi kerja : $\operatorname{Good}(\mathrm{C}) \quad=+0,02$

Konsistensi : $\operatorname{Good}(\mathrm{C}) \quad=+0,01$

Jumlah $=0,19$

$$
\mathrm{p} 1=1+0,19=1,19
$$

Bagian badan yang di pakai $\quad=\mathrm{D}=5$

Pedal kaki $=\mathrm{G}=5$

Penggunaan tangan $\quad=\mathrm{H}=0$

Kondisi mata dengan tangan $\quad=\mathrm{J}=2$

Peralatan $\quad=\mathrm{P}=2$

Berat $\quad=\mathrm{B}-5=13$

Jumlah $\quad=27=0,27$

$$
\text { p2 }=1+0,27=1,27
$$

Maka faktor penyesuaiannya adalah sebagai berikut:

$$
R_{f}=P_{1} x P_{2}=1,19 \times 1,27=1,5
$$

Maka waktu normalnya:

$$
\begin{aligned}
\mathrm{Wn} & =\mathrm{Ws} \times \mathrm{Rf} \\
& =0,01 \times 1,51=0,013
\end{aligned}
$$

8) Perhitungan waktu baku (Wb)

Allowance $=$ Tenaga yang di keluarkan $=15 \%$

Sikap kerja

$=2 \%$

Gerakan kerja

$=5 \%$

Kelelahan mata$$
=6 \%
$$

Keadaan temperatur$$
=13 \%
$$

Keadaan atmosfer 
$\begin{aligned} \text { Keadaan lingkungan } & =6 \% \\ & =47 \%\end{aligned}$

Jumlah

$$
\begin{aligned}
\mathrm{Wb} & =\mathrm{Wn} \cdot \frac{100 \%}{100 \%-a l l} \\
& =0,013 \cdot \frac{100 \%}{100 \%-47 \%} \\
& =0,013 \cdot \frac{100 \%}{53 \%} \\
& =0,013 \cdot 1,887 \\
& =0,02 \text { Menit }
\end{aligned}
$$

9) $\mathrm{BK}=\frac{\text { waktu baku }}{\text { total waktu pengamatan }} \times 100 \%$

$$
=\frac{0,02}{1540} \times 100 \%=108 \%
$$

4. Perhitungan Beban Kerja NASA-TLX Pekerja A Data perhitungan NASA-TLX di dapatkan dari kuesioner yang di bagikan pada setiap Karyawan PT.Tokai Dharma Indonesia Plant II, yaitu kuesioner perbandingan indikator berpasangan dan kuesioner pembobotan indikator.

Tabel VI

Pengukuran Beban Mental Pekerja A Dengan NASA-TLX

\begin{tabular}{llll}
\hline $\begin{array}{l}\text { Indikator Beban Kerja } \\
\text { Mental }\end{array}$ & Weight & Rating & Product \\
\hline Kebutuhan Mental (KM) & 2 & 75 & 150 \\
Kebutuhan Fisik (KF) & 4 & 90 & 360 \\
Kebutuhan Waktu (KW) & 3 & 70 & 210 \\
Performa Kerja (PK) & 1 & 70 & 70 \\
Tingkat Frustasi (TS) & 2 & 85 & 170 \\
Usaha Fisik Mental (U) & 3 & 90 & 270 \\
Total & 15 & 480 & 1230 \\
\hline Mean WWL Score & 82 & &
\end{tabular}

(Sumber: Kuesioner NASA-TLX Pekerja A)

Ketika dimunculkan dengan seluruh tabel dan gambar grafik di atas, tentunya kita tidak mudah untuk memahami persentase produktif dan beban kerja pada pekerja di PT. Tokai Dharma Indonesia Plant II, oleh karena ini untuk mempermudah mengamati dan

\begin{tabular}{|c|c|c|c|c|c|c|c|c|c|c|c|c|c|}
\hline 50 & 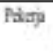 & $\begin{array}{l}\text { Kar } \\
\text { houtidif }\end{array}$ & $\begin{array}{l}3 x-10 \\
\text { Phatafif }\end{array}$ & EXA & $B 59$ & $P$ & $\mathrm{~N}^{\prime}$ & $\mathrm{N}$ & $\begin{array}{c}\text { Mans } \\
\text { forpuntue }\end{array}$ & 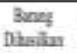 & $W z$ & $\mathrm{Win}_{\mathrm{n}}$ & 6 \\
\hline 1 & A & 115 & बता & 134 & 5 & $2 \pi$ & 34 & 450 & 20 & 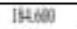 & घII & 0,05 & 85 \\
\hline 2 & B & 136 & $0 \pi$ & 14 & 155 & $Q 70$ & 34 & 150 & $2 x$ & 1001000 & eti & wat & $\leq 12$ \\
\hline 3 & c & 152 & oss & is & 155 & ass & X. & 150) & 20) & 18xenen & III & ough & $B$ \\
\hline 4 & D & 197 & an & 14 & 65 & $a x$ & 34. & 45i. & 20 & $2 x+20$ & ull & aef & ts: \\
\hline 5 & E & 14 & Qua & te & 153 & 0,06 & के & 450 & 2n) & 17.90 & ent & ard & te \\
\hline 6 & E & 148 & $\omega 0$ & 31 & 25 & कst & $7 \theta$ & (5) & 20 & 3143010 & ent & exel & $\angle B$ \\
\hline 7 & G & 141 & abs & est & 154 & $\Delta A B$ & $\$ 6$ & 450 & 2n) & 231300 & et & 0,01 & is \\
\hline 8 & H & $13 t$ & הत & 4.5 & 158 & Q7] & 33. & 450 & 20) & $183: 20$ & ent & woz & 186 \\
\hline 4 & 1 & 16 & 0.4 & 17 & 18 & 0,4 & 45 & (5) & 20 & 25610 & EII & ait & bet \\
\hline n & 1 & 115 & 8.74 & of & 190 & 274 & 28 & 450 & 20 & 172990 & et & $0, k 4$ & is \\
\hline II & E. & 14) & Q & is & 154 & $Q \Delta B$ & \$3. & 450 & 20 & 136200 & ett & aws & 10 \\
\hline I2 & $L$ & 143 & as & 106 & 153 & ass & 3 & 450 & 200 & 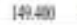 & Ell & ands & bet \\
\hline
\end{tabular}
menarik kesimpulan dari analisis tersebut, penulis membuat tabel rekapitulasi pekerja yang di teliti, berikut adalah tabelnya:

Tabel VII

\begin{tabular}{|c|c|c|c|c|c|c|c|c|c|}
\hline \multirow[b]{2}{*}{ 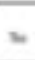 } & \multirow[b]{2}{*}{ map } & \multicolumn{6}{|c|}{ Whe } & \multirow[b]{2}{*}{ Nest } & \multirow[b]{2}{*}{ svt } \\
\hline & & का & $y$ & $\approx$ & $\bar{\alpha}$ & $\pi$ & $t$ & & \\
\hline$T$ & $\mathrm{~s}$ & 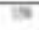 & 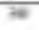 & श्र & $\pi$ & $n$ & 5 & $\mathrm{Cos}$ & e \\
\hline 2 & $*$ & 2 & s & $2 a$ & 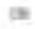 & $=$ & is & 매 & $E$ \\
\hline 3 & c & $=$ & $\omega$ & 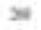 & $x$ & in & $=$ & 19 & tin \\
\hline * & $=$ & 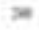 & $3 *$ & in & is & , & e & inat & 3 \\
\hline 3 & E & 2in & $\mathrm{m}$ & $=$ & 10 & in & $\infty$ & 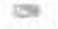 & e \\
\hline . & $r$ & $=$ & is & $=$ & m & $\approx$ & $=$ & ini & 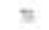 \\
\hline$t$ & $=$ & as & $=$ & $=$ & $=$ & $=$ & $=$ & $w$ & $=$ \\
\hline , & $=$ & 2 & 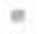 & $=$ & se & $i$ & $m$ & wa & $e$ \\
\hline , & 1 & $=$ & b & in & is & $M$ & se & in & $=$ \\
\hline * & 1 & in & I & in & ie & x & $=$ & in & 3 \\
\hline in & $x$ & In & $m$ & $\mathbf{m}$ & is & 20 & $=$ & $\Leftrightarrow$ & H \\
\hline a & $\mathrm{i}$ & $=$ & $s$ & an & $=$ & $3=$ & $=$ & $=$ & *i \\
\hline \multicolumn{9}{|c|}{ Smevit } & $=$ \\
\hline
\end{tabular}

Hasil Rekapitulasi Work Sampling

(sumber: Pengolahan Data)
Tabel VIII

Hasil Rekapitulasi Beban Kerja Mental NASA-TLX

(Sumber: Pengolahan Data)

Dari hasil di atas maka kita dapat menganalisa hasil produktivitas dan beban kerja operator produksi di PT. Tokai Dharma Indonesia Plant II, dimana secara keseluruhan pekerja yang memiliki persentase produktif paling tinggi yaitu pekerja $\mathrm{J}$ (Fatma) dengan nilai $74 \%$. Sedangkan pekerja dengan persentase terendah adalah pekerja C (Rizaldi Fadilah) dan I (Sanusi) dengan nilai 64\%.

Penyebab terjadinya produktivitas rendah yaitu karena adanya aktivitas mengobrol dan sering istirahat serta menunggu mesin berjalan. Berdarkan hasil analisis dengan perhitungan persentase produktifitas pekerja di PT. Tokai Dharma Indonesia Plant II, hal ini membuktikan bahwa produktif atau tidaknya suatu pekerja dalam melakukan aktivitas selama 5 hari tidak mempengaruhi oleh besar kecilnya kriteria pada masing-masing pekerja.

Suatu beban kerja dapat dikatakan optimal dengan nilai beban kerja sejumlah $100 \%$. Dari tabel di atas dapat di ketahui bahwa beban kerja yang di alami oleh masing-masing pekerja di PT.Tokai Dharma Indonesia Plant II sangat tinggi karena lebih dari $100 \%$ dengan nilai tertinggi yaitu pekerja C (Saiful Hidayat) dengan beban kerja $118 \%$. Yang meyebabkan tingginya beban kerja pada pekerja operator di PT. Tokai adalah karena karyawan terlalu banyak mengejar target serta beban material yang cukup berat dan untuk tidak produktifnya karena karyawan terlalu lama dan sering menunggu mesin produksi berjalan mengakibatkan banyak pekerjaan yang tidak produktif. Untuk beban kerja mental paling tinggi yaitu Pekerja E (Haryadi) dengan beban kerja mental sebesar $83 \%$ yang di akibatkan pekerjaan sering melibatkan pekerjaan otot seperti mengangkat, mendorong dan lain-lain serta besarnya tekanan yang di rasakan mengenai waktu penyelesaian pekerjaann agar bisa mencapai target yang inginkan. Selain itu operator hanya bertugas untuk memasukan material kedalam mesin produksi dan memperbaiki mesin jika mesin rusak/macet. Semakin rendahnya beban kerja operator produksi di PT.Tokai Dharma Indonesia maka semakin tinggi kinerja pegawai terhadap hasil produksi yang di jalankan. Jika masing-masing pekerja di haruskan untuk melakukan pekerjaanya sesuai dengan tugasnya masing-masing, persentase produktifitasnya pekerja tersebut cenderung kecil 
mulai dari $64 \%$ hingga $74 \%$, meskipun beban kerja yang dialamai masing-masing pekerja cenderung rendah karena bernilai kurang dari $100 \%$ tetapi prestasi kerja yang tergolong baik.

\section{CONCLUSIONS}

1. Dari hasil di atas maka kita dapat menganalisa hasil produktivitas dan beban kerja operator produksi di PT. Tokai Dharma Indonesia Plant II, dimana secara keseluruhan pekerja yang memiliki Persentase produktif tertinggi yaitu dengan jumlah $74 \%$ pekerja $\mathrm{J}$ (Fatma)

2. Sedangkan pekerja dengan persentase terendah adalah pekerja C (Rizaldi Fadilah) dengan nilai 64\%.

3. Penyebab terjadinya produktivitas rendah yaitu karena adanya aktivitas mengobrol dan sering istirahat serta menunggu mesin berjalan.

4. Suatu beban kerja dapat dikatakan optimal dengan nilai beban kerja sejumlah $100 \%$. Dari tabel di atas dapat di ketahui bahwa beban kerja yang di alami oleh masing-masing pekerja di PT.Tokai Dharma Indonesia Plant II sangat tinggi karena lebih dari 100\% dengan nilai tertinggi yaitu pekerja $\mathrm{C}$ (Saiful Hidayat) dengan beban kerja $118 \%$. Untuk beban kerja mental paling tinggi yang di hitung menggunakan metode NASA-TLX adalah pekerja E (Haryadi) dengan skor rata-rata yaitu $72 \%$ yang berarti beban kerja tinggi.

5. Yang meyebabkan tingginya beban kerja pada pekerja operator di PT. Tokai adalah karena karyawan terlalu banyak mengejar target serta beban material yang cukup berat dan untuk tidak produktifnya dikarenakan karyawan terlalu lama dan sering menunggu mesin produksi berjalan mengakibatkan banyak pekerjaan yang tidak produktif.

Solusi untuk mengatasi beban kerja yang tinggi yaitu dengan menyesuaikan kemampuan fisik dan mental pekerja serta memberi pekerja kesempatan pekerja untuk mengebangkan karir dengan mengikutkan beberapa pekerja untuk melakukan pelatihan agar terbiasa dan dapat meningkatkan produktivitas

\section{REFERENCES}

[1] Andriani, P. D., \& Anugrah, B. (2017). Aplikasi Metode Work Sampling Untuk Menghitung Waktu Baku Dan Kapasitas Produksi Pada Industri Kramik. Jurnal Teknik Industri Vol.10(1)

[2] Anggun, L., Hendy, T., \& Filscha, N. (2018). Analisis Produktivitas Kasir Guna Menentukan Beban Kerja Menggunakan Work Sampling Pada Gerai Makanan Cepat Saji. Jurnal Teknik Industri. Vol.2(3).

[3] Anton, M., \& Haryono. (2015). Analisis Beban Kerja Fisik Dan Mental dengan Menggunakan Work https://doi.org/10.30998/joti.v3i2.10026
Sampling dan NASA-TLX Untuk Menentukan Jumlah Operator. Jurnal Teknik Industri. Vol.3(5)

[4] Apple, M. (2016). Tata Letak Pabrik dan Pemindahan Bahan Edisi Ketiga. Bandung : ITB Press.

[5] Darmadi, (2017). Manajemen Sumber Daya Manusia Kekepalasekolahan. Sleman : CV. Budi Utama.

[6] Hayati, Z., \& Adrian, A. (2019). Analisis Beban Kerja Mental Karyawan Menggunakan Metode NASA-TLX (Studi Kasus: PT. Universal Tekno Reksajaya Pekanbaru, Riau). Jurnal Teknik Industri. Vol.6(1).

[7] Herdiansyah, T. Y., \& Aulawi, H. (2018). Analisis Beban Kerja Untuk Menentukan Jumlah Kebutuhan Tenaga Kerja Divisi Administrasi Umum di PT. Indonesia Power Unit Jurnal Kalibrasi. Vol.16(2).

[8] Huming, N. (2015). Manajemen Produksi Modern. Jakarta : PT. Bumi Aksara.

[9] Jaka, R., Nurul, H., \& Silvia, F. U. (2019). Analisis Beban Kerja Mental Pada Staf Unit Pelaksana Tekis Dengan Menggunakan Metode NASA TLX (Studi Kasus :Universitas Teknologi Sumbawa). Jurnal Teknik Industri. Vol.3(12).

[10] Lestari, P., \& Trisyulianto, E. (2018). Analisis Beban Kerja dan Kebutuhan Karyawan Direktorat Operasional Kantor Pusat PT Perkebunan Nusantara VIII. Jurnal Manajemen dan Organisasi. Vol.9(3).

[11] Mulyanti, D., Naza, N., \& Aisyah, O. (2020). Pengukuran Beban Kerja Mental dan Fisik dengan Menggunakan Metode NASA Task Load Index. Jurnal: Teknik Industri. Vol.1(2).

[12]Nur, F., \& Ihwan, K. (2017). Tingkat Produktivitas Pekerja Penyungkil Kelapa Dengan Menggunakan Metode Work Sampling. Jurnal Teknik Industri. Vol.8(1).

[13] Rahdiana, N., \& Sukarman. (2021). Pengukuran Beban Kerja Mental Bagian Penjualan PT. Pindo Deli di Masa Covid-19 dengan Metode NASA-TLX. Jurnal Teknik Industri. Vol.23(1).

[14] Rahmaniyah, D. A., \& Irwan, I. (2016). Analisis dan Perancangan Sistem Kerja. Sleman : CV. Budi Utama.

[15] Retno, W., Emmy, N., \& Erlin, N. I. S. (2019). Analisis Beban Kerja Fisik dan Mental Petugas Cleaning Service Menggunakan Metode Work Sampling dan NASA-TLX Jurnal Teknik Industri. Vol.6(3).

[16] Ricky, V. M. (2019), Analisis Produktifitas \& Efisiensi, Jakarta : PT. Gramedia.

[17] Rivianto (2014) Dalam Buku, Indiastandi Herdianto, (2015). Ergonomi Suatu Pengantar. Bandung : PT. Remaja Rosdakarya.

[18] Rosidah (2015) Dalam Buku, Yano, N. B. (2019). ERGONOMI Dasar- dasar Studi Waktu \& Gerakan Untuk Analisis \& Perbaikan Sistem Kerja. Yogyakarta : CV. ANDI OFFSET.

[19] Tohardi (2015) Dalam Jurnal, Hendy,T., Ruth, E. R., Fuji, R. W., \& Glisina, D. R. (2019). Analisis Produktivitas Operator Kasir Menggunakan Metode Work Sampling: Studi Kasus Gerai Chatime Mangga Besar. Jurnal Teknik Industri. Vol.7(2).

[20] Vera, M. A. (2016). Analisa Beban Kerja Operator Inspeksi Dengan Metode NASA-TLX (TASK LOAD INDEX) DI PT. XYZ. Jurnal Teknik Industri. Vol.7(2). 